\title{
Study on Spatial Imbalance and Determinants of E-Commerce Development in Zhejiang, China
}

\author{
Haidong Zhong $\mathbb{D}^{1}{ }^{1}$ Jinhui Zhang $\mathbb{D}^{2},{ }^{2}$ Shaozhong Zhang $\mathbb{D}^{3}$, and Wen Zheng $\mathbb{D}^{1}$ \\ ${ }^{1}$ Digital Industry Research Institute, Zhejiang Wanli University, Ningbo 315100, Zhejiang, China \\ ${ }^{2}$ Logistics and E-Commerce School, Zhejiang Wanli University, Ningbo 315100, China \\ ${ }^{3}$ College of Information and Intelligence Engineering, Zhejiang Wanli University, Ningbo 315100, China \\ Correspondence should be addressed to Wen Zheng; zhengwen0722@163.com
}

Received 16 November 2020; Revised 23 December 2020; Accepted 6 January 2021; Published 18 January 2021

Academic Editor: Chonghui Zhang

Copyright (c) 2021 Haidong Zhong et al. This is an open access article distributed under the Creative Commons Attribution License, which permits unrestricted use, distribution, and reproduction in any medium, provided the original work is properly cited.

\begin{abstract}
As a world-famous and well-developed e-commerce region, the development of e-commerce in Zhejiang province has always attracted people's wide attention. Based on publicly available e-commerce transaction-related data, basic geographic data, and regional economic and social development data, we use the Gini coefficient to measure the imbalance of e-commerce development in Zhejiang province during 2017-2019. With the help of spatial analyst tools in ArcGIS desktop, the cluster and outlier analysis method is used to study the spatial pattern of e-commerce development in the province at the district or county-level city scale. To explore the causes of spatial aggregation and imbalance of e-commerce in Zhejiang province quantitatively, the paper proposes a geographical weighted regression (GWR) model with 15 economic and social development-related indicators. GWR and ordinary least squares (OLS) analysis indicate that 5 of the 15 selected indicators are highly related to the development of regional e-commerce development in Zhejiang, China.
\end{abstract}

\section{Introduction}

As the largest e-commerce market in the world, China's e-commerce has maintained rapid development for many years. According to the report on the development of e-commerce in China, China's e-commerce volume reached 34.81 trillion yuan, of which the online retail sales reached 10.63 trillion yuan, which is year-on-year growth of $16.5 \%$. The online retail sales of physical goods reached 8.52 trillion yuan, accounting for $20.7 \%$ of the total retail sales of consumer goods. The number of e-commerce employees reached 51,256,500 (http://www.chinanews.com/cj/2020/0630/9225677.shtml). With the continuous expansion of the application fields and application depth of e-commerce, various regions have introduced policies to promote the development of local e-commerce and improved the service systems such as credit certification, payment guarantee, and brand promotion, training mechanism for scientific and technological talents, and development of logistics distribution. The development of e-commerce has created a lot of job opportunities for urban and rural residents and become one of the important drivers for the sustained economic growth. Therefore, the spatial distribution characteristics of e-commerce can reflect the development of China's economy and information technology to a large extent.

Due to the accumulation of many economic and social development related factors, the spatial distribution of the development level of e-commerce in China is obviously different. From four aspects, the development level, growth potential, application penetration, and support environment, China's E-Commerce Development Index Report (2018) (http://www.cac.gov.cn/2019-05/29/c_1124554997. $\mathrm{htm}$ ) evaluated the development level of e-commerce in each province in China comprehensively. According to the report, the integration of e-commerce and traditional economy is deepening, and the characteristics of horizontal spatial agglomeration of e-commerce development are 
obvious. In 2018, Guangdong province, Zhejiang province, Beijing city, Shanghai city, and Jiangsu province are the top five online retailers at the province (municipality directly under the central government) scale, accounting for $72.3 \%$ of China's online retail sales [1]. The overall development of e-commerce at the province scale is basically "strong in the east and weak in the west," and the cluster effect is emerging. The spatial distribution characteristics of e-commerce development also reflect the imbalance of regional economic and social development to a large extent.

Zhejiang province ranks the second in online retail sales of China. Meanwhile, Hangzhou city (the provincial capital city of Zhejiang province) is the home to the world's super e-commerce giant Alibaba Group (https://www.alibaba. com/). Currently, among Chinese e-commerce platforms, TMALL, owned by Alibaba Group, takes the first place in the online retail market with a share of $57.7 \%$, which has an obvious driving effect on the traditional economy. Zhejiang province supports the development of new forms of business, such as Alibaba's new retail store Super Species, NetEase Koala, and NetEase experience stores, and helps Hangzhou build a new retail benchmark city. By promoting county-level e-commerce development vigorously, Zhejiang province has built 1,253 e-commerce villages, over 4,500 county-level e-commerce public service centres and villagelevel e-commerce service stations. Analysing the spatial distribution pattern and its influencing factors of the level of e-commerce development from the perspective of county region is meaningful for promoting the development of e-commerce in county regions.

Under the background of the in-depth development of the Internet, regional development is gradually integrated, and the energy radiation of the regional development of the central city is gradually transferred to the space of the district and county level, and the county region has become an important node of the network development. Analysing the spatial connection of county economic and social development factors can better adapt to the demand change of modern service industry development in the new era.

Therefore, this paper explores the imbalance of e-commerce development at provincial and municipal scales. Meanwhile, it studies the relationship between economic and social development and the spatial pattern of e-commerce development at the district or county-level city scale. It is hoped that the study can provide theoretical support and scientific basis for the collaborative development of e-commerce and other related industries in the exploration at the county level. The main contributions of this paper lie in the following three aspects:

(1) We measure the imbalance of regional e-commerce development in Zhejiang, China quantitatively. Referring to the internationally widely used measures of income gap between residents of countries or regions, we calculate the Gini coefficient based on online retail sales at both city scale and district or county-level city scale.

(2) We employ a geographical perspective to study the spatial pattern of e-commerce development in
Zhejiang, China. Based on the publicly available e-commerce development data and basic geographic information data, we use GIS technology and spatial statistical analysis tools in ArcGIS software to investigate the spatial aggregation pattern of online retail sales at the district or county-level city scale.

(3) We attempt to explore the reasons for the spatial distribution of online retail sales in Zhejiang, China. Referring to the existing research, we establish a geographical weighted regression (GWR) model to explain the relationship between regional e-commerce development and economic and social development. To verify the fitness of the proposed model, we use spatial autocorrelation analysis, geographical weighted regression analysis, etc., to analyse quantitatively with publicly available economic development related data, such as GDP, disposable fiscal income, and income of urban residents.

\section{Literature Review}

In recent years, booming e-commerce has attracted considerable scholars' attention to the impact of this kind of online transaction pattern. They find that the need for retail stores and facilities in commercial cores is somewhat challenged in the e-commerce scenario: the need for trips to bustling downtown shopping locations decreases rapidly, and supermarkets, shops, etc. are increasingly replaced by warehousing, retail outlets, or other types of storage facilities far from downtown cities [2]. To accomplish transactions based on virtual cyberspace, it requires a reconstruction of upstream, midstream, and downstream industrial supply chains and logistics systems from consumers' point of view $[3,4]$. Accompanied by the rapidly growing global e-commerce market, cities all over the world are experiencing an operational change from physicality to virtuality, and the pattern of urban planning, enterprise production, and sales and economic and social development modes are also changing accordingly [5].

As an important part of information economy, e-commerce is of special significance in China and has played a very important role in improving people's lives. In addition to the progress made in the use of e-commerce among individuals, it is also important and meaningful to understand the extent and importance of differences between geographical regions $[6,7]$. There are many indicators published to measure the level of access to and use of information and communication technologies (ICTs), such as the ICT Development Index released by the International Telecommunication Union [8], the Digital Economy and Society Index [9] announced by the European Commission in 2017, and the Networked Readiness Index [10] reported by the World Economic Forum in 2017. However, all these indicators were developed at the country scale.

As early as 2002, the spatial econometric method has been used to explore the spread of e-commerce in various countries and the impact of the policy environment on the development path of e-commerce [11]. Many studies focus 
on regional e-commerce competitiveness and the impact of e-commerce on local economic development based on indices irregularly released by many well-known e-commerce enterprises such as Alibaba Group (https://www. alibabagroup.com/en/global/home) and Jingdong Group (https://corporate.jd.com/home). AliResearch (http://www. aliresearch.com/) was the first research institute to publish a nationwide Alibaba e-commerce Development Index (eEDI) using the number of sellers, the number of buyers, and e-commerce transaction volume on Taobao (http://www. taobao.com/) and TMall (http://www.tmall.com/) platforms in 2015. eEDI is the weighted average of the Internet business index and the online shopping index. The value of eEDI ranges from 0 to 100 , and the higher the value, the higher the development level of regional e-commerce. In addition, there are some well-known universities and research institutions such as the National Engineering Laboratory for E-commerce Transaction Technology of Tsinghua University and the Chinese Academy of Social Sciences, who jointly publish the China E-Commerce Development Index Report (http://necc.nufe.edu.cn/) annually. There are a great many existing studies that use eEDI or the China e-commerce Development Index (including size index, growth index, and penetration index) and support index to evaluate the development level of regional e-commerce [12-14]. However, only the calculation methods of eEDI and the China E-Commerce Development Index are disclosed, and the raw data that generate them are completely unavailable. The authority of these regional e-commerce development inequality or imbalance evaluation indicators also needs to be further improved.

There is a line of research on the factors affecting the development of regional e-commerce at the provincial level and city level. Studies show there is an obvious spatial aggregation in the development of e-commerce in China: the level of e-commerce in the eastern coastal areas is higher than that in the western inland areas; significant high-high spatial aggregation areas mainly exist in Zhejiang province, Jiangsu province, Fujian province, etc.; significant low-low spatial aggregation areas are mainly located in Tibet Autonomous Region, Gansu province, Qinghai province, and so on [15-17]. The spatial difference of the e-commerce development level between provinces and regions does not change obviously in China, and it shows a development trend of gradient reduction and staggered distribution from the east coast to the interior [17]. In addition, the least square method, spatial lag model, spatial error model, and geographic regression analysis based on eEDI show that determinants of e-commerce development at the county level include the balance of savings deposits of urban and rural residents, urbanisation rate, per capita GDP, proportion of nonagricultural industries, disposable income of urban residents, mobile phone users, Internet users, and fixed-line phone users [16, 18-20].

Overall, the research on the spatial distribution pattern of e-commerce is mostly conducted at the national or provincial scales, but it lacks the scale of city and county or county-level city studies in China. Although many studies select the number of consumer-to-consumer (C2C) stores
[21] or the number of Taobao towns and Taobao villages [22] to establish a regional e-commerce development level evaluation system, they use only $\mathrm{C} 2 \mathrm{C}$ data from Alibaba and much of the data is not publicly available or not regularly released.

In this paper, we attempt to further analyse the spatial distribution pattern of the regional e-commerce development level in Zhejiang, China, from the perspective of county or district region scale based on publicly available and regularly release statistical yearbook data. Furthermore, we focus on applying spatial statistical analysis methods to explore the relationship between the regional e-commerce development pattern and some economic and social development factors. We hope the research results can provide some meaningful references to the regional policy making process to promote e-commerce and social and economic development.

\section{Study Area and Data Sources}

3.1. Study Area. Zhejiang province is located in the core area of the Yangtze River Delta Economic Zone in China, and it is bounded by east longitude $118^{\circ} 01^{\prime}-123^{\circ} 10^{\prime}$ and north latitude $27^{\circ} 02^{\prime}-31^{\circ} 11^{\prime}$, with an area of 105,500 square kilometres (as shown in Figure 1). By the end of 2019, the province had 11 cities under its jurisdiction (including two subprovincial cities), 20 county-level cities, 32 counties, one autonomous county, and 37 municipal districts. Zhejiang province slopes from southwest to northeast with complicated terrain, it has a humid monsoon climate, and natural conditions are superior. The total resident population of the province was 58.5 million at the end of 2019 and 1.13 million more than the previous year.

Zhejiang province is one of the provinces with the smallest economic disparities in China, with Hangzhou city, Ningbo city, Shaoxing city, and Wenzhou city as its four economic pillars. The world's largest port, the NingboZhoushan Port, is located in the province. In 2019, gross domestic product (GDP) of Zhejiang province reached 6,235.2 billion yuan ( $\$ 903.9$ billion), 6.8 percent higher than the previous year at comparable prices, and the per capita GDP was 107,624 yuan $(\$ 15,601)$. In October 2019 , it was selected as the National Digital Economy Innovation and Development Pilot Zone.

3.2. Data Source. All the e-commerce transaction-related data used in this paper come from the Department of Commerce of Zhejiang province (http://www.zcom.gov.cn/ ). The data contain transaction volumes of both e-commerce and cross-border e-commerce in each municipal district (county or county-level city) in Zhejiang province from 2017 to 2019. In addition, the data are published monthly and publicly available. After simple operations such as splitting and merging, quarterly data and yearly data can be obtained correspondingly.

Indicators used to explore e-commerce and regional economic and social development, such as GDP, per capita GDP, local fiscal revenue, and transportation expenditure, 


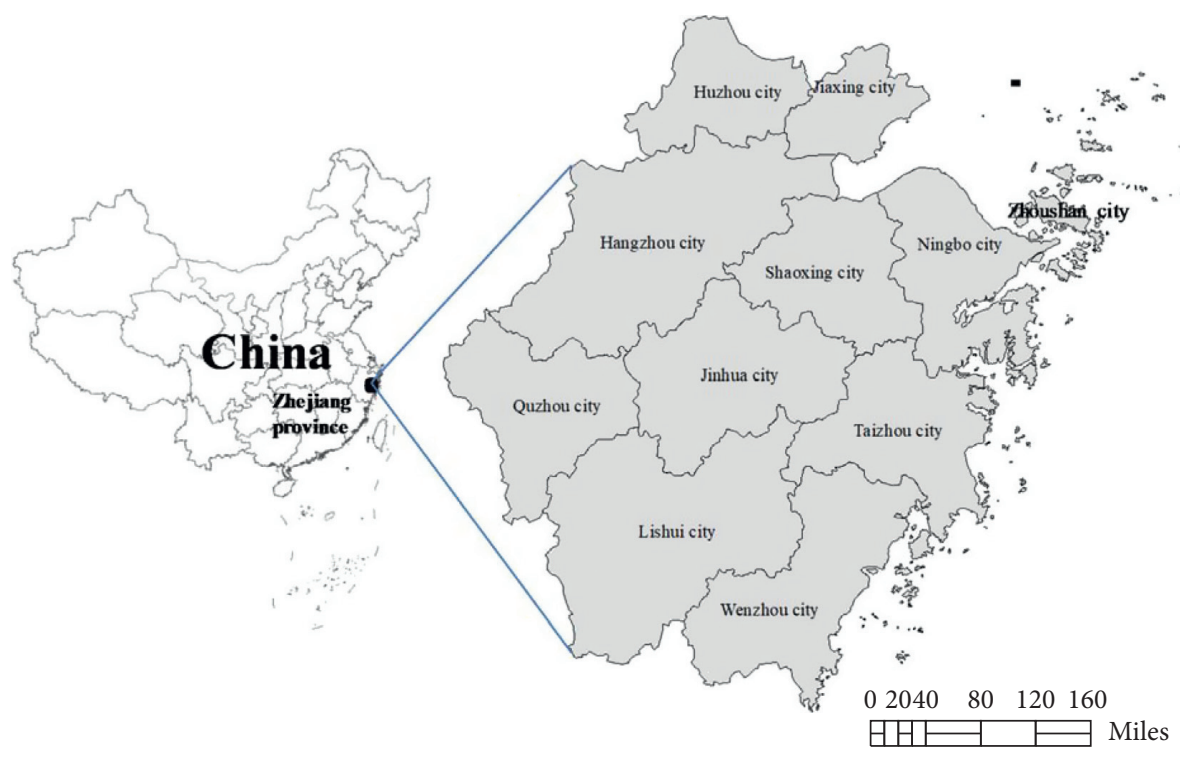

FIgURE 1: The geographical location of Zhejiang province.

are collected from the 2019 statistical yearbook of 11 cities in Zhejiang province. Basic geographic data of the province, including area, city, and county level or county boundaries, are gathered from national basic data and public datasharing websites.

\section{Research Methods}

4.1. Spatial Imbalance Analysis. The paper employs the Gini coefficient [23], which is a common index used to measure the income gap of residents in a country or region, to analyse the spatial imbalance of e-commerce development at the county level of Zhejiang province. The specific method is shown in the following formula:

$$
\text { Gin }=\sum p_{k}^{2} \lambda_{k} G_{k}+\frac{1}{2} \sum p_{k} p_{h}\left|\lambda_{k}-\lambda_{h}\right|+R,
$$

where Gin is the overall Gini coefficient that is adopted to measure the spatial imbalance degree of e-commerce development at the county scale, $p_{k}$ represents the share of group $k, \lambda_{k}$ represents the ratio of the average regional e-commerce transaction volume of group $k$ to the entire sample value, and $G_{k}$ is the Gini coefficient of group $k$. The first term on the right of the formula reflects the intragroup gap or disequilibrium; the second term reflects the intergroup disequilibrium; and $R$ is the remaining term, reflecting the interaction caused by the overlap between different groups.

4.2. LISA Analysis. Local indicators of spatial association (LISA) analysis is commonly used to explore the local index of spatial relations. In a LISA graph, clustering is divided into four cases, high-high, low-high, low-low, and high-low, each of which identifies an area and its relationship to its neighbours. High-high indicates that a high-level area is surrounded by other high levels; low-high indicates that a low-level area is surrounded by other high-level areas; low- low indicates that a low-level area is surrounded by other low-level areas; and high-low indicates that a high-level area is surrounded by other low-level areas [24].

4.3. Spatial Autocorrelation Analysis. Spatial autocorrelation analysis explores spatial dependency effects between different variables with a set of statistical methods in conventional linear statistical models. It originates from biometrics, and it has become one of the basic methods of theoretical geography [25]. Moran's I is one of the most popular methods to measure the overall pattern across a geographic landscape and degree of interdependence between different locations $[26,27]$. Moran's I measures spatial autocorrelation by both factor location and factor value, which can be applied to evaluate whether the expressed patterns are clustering, discrete, or random. It can be calculated by the following formula:

$$
I=\frac{n}{S_{0}} \frac{\sum_{i=1}^{n} \sum_{j=1}^{n} w_{i, j} z_{i} z_{j}}{\sum_{i=1}^{n} z_{i}^{2}}
$$

where $z_{i}$ is the dispersion value between the observed value and the value of expectation at location $i, w_{i, j}$ is the proximity relation value of locations $i$ and $j, n$ is the sum of all observation locations, $S_{0}$ is the sum of all proximity relation values, and $z_{i}$ can be calculated with the following formula:

$$
z_{i}=\frac{I-E[I]}{\sqrt{[V]}}
$$

where $E[I]=(1 /(n-1))$ and $[V]=E\left[I^{2}\right]-E[I]^{2}$.

Moran's I $>0$ represents positive spatial correlation, and the greater the value, the more obvious the spatial correlation. Moran's $\mathrm{I}<0$ represents negative spatial correlation, and the smaller the value, the greater the spatial difference. Otherwise, Moran's I $=0$, and the space is random. With the help of the tool kit for spatial statistical analysis in ArcGIS software, spatial pattern of a set of factors and related 
attributes can be measured by calculating the value of Moran's I index, the $z$-score, and the $p$ value at the same time. The $z$-score is used to identify the calculated spatial pattern, and the $p$ value is an area approximation based on a curve of a known distribution. Very high or very low (negative) $z$-scores appear at both ends of the normal distribution, which are associated with very small $p$ values. If the $z$-score is smaller than -1.96 and or greater than 1.96 , the calculated statistical result is basically reliable at the confidence level of 0.05 . If the $z$-score is smaller than -1.96 , the calculated distribution is discrete. Otherwise, the calculated distribution can be viewed as random [28].

4.4. GWR Analysis. GWR is a local form of linear regression used to model spatial variation relationships. It extends the general linear regression model. In GWR, the regression coefficient of a specific location is not assumed constant as estimated by using all the information, but it is a variable obtained by using the subsample information of the observed values of the neighbourhood region. By adapting the regression equation to each element in the dataset, GWR provides a local model for the variables or processes you are trying to understand/predict. The GWR model can be represented as follows [29]:

$$
y_{i}=\beta_{0}\left(u_{i}, v_{i}\right)+\sum_{i=1}^{k} \beta_{i}\left(u_{i}, v_{i}\right) x_{i k}+\varepsilon_{i},
$$

where $\beta_{i}$ represents a parameter vector that needs to be estimated, $\left(u_{i}, v_{i}\right)$ is geographical coordinate value at location $i, \beta_{i}$ is a $k+1$ function of $\left(u_{i}, v_{i}\right)$, and $\varepsilon_{i}$ is the random error at location $i$ and satisfies the assumptions of zero mean, homoscedasticity, and independence. In GWR, each region has a corresponding estimation function, whose logarithmic likelihood function can be expressed as $[30,31]$

$$
\begin{aligned}
\log L & =L\left[\beta_{0}(u, v), \beta_{1}(u, v), \ldots, \beta_{k}(u, v) \mid M\right] \\
& =-\frac{1}{2 \sigma^{2}} \sum_{i=1}^{n}\left[y_{i}-\beta_{0}\left(u_{i}, v_{i}\right)\right]-\sum_{j=1}^{k} \beta_{k}\left(u_{i}, v_{i}\right) x_{i}+\alpha,
\end{aligned}
$$

where $\alpha$ is a constant, $M=\left[y_{i}, x_{i j},(u i, v i)\right.$, $i=1,2,3, \ldots, n, j=1,2,3, \ldots, k]$, and $y_{i}$ is an approximate value of $\beta_{k}\left(u_{i}, v_{i}\right)$.

\section{Imbalance and Spatial Pattern of E-Commerce Development in Zhejiang Province}

5.1. Analysis on Unbalanced Development of E-Commerce. Statistics show that the development level of e-commerce varies greatly among cities in Zhejiang province. As shown in Figure 2, the development of Hangzhou city is far ahead compared to other cities, whether measured in terms of online sales or online spending from 2017 to 2019. In terms of online retail sales, the gap between Hangzhou city and other cities is widening during 2017-2019. In 2017,
Hangzhou city accounts for $32.3 \%$ of online sales in Zhejiang province, and the proportion rises to $36.8 \%$ in 2019. Also, Figure 2 indicates that the development level of e-commerce in Quzhou city, Zhoushan city, and Lishui city is relatively low.

To draw a clear profile of the imbalance of e-commerce development in recent years, we use the Gini coefficient and its decomposition method to measure the degree of imbalance of online retail sales in cities of Zhejiang province. Due to data statistics and public data access restrictions, only 3 years' online retail sales of cities in the province are collected. However, these data reveal a very unbalanced state of e-commerce development at the provincial scale from 2017 to 2019 (as shown in Figure 3). Even at the lowest point in 2018, the Gini coefficient was 0.491, which indicates a large e-commerce development gap, according to international practice. In 2019, this value reached 0.525 , which represented a wide gap of e-commerce development in Zhejiang province.

To further study the balanced development status of e-commerce at the city level, we collect online retail sales data of all districts and county-level cities in Zhejiang province from 2017 to 2019. The Gini coefficient of online retail sales in cities of the province (as shown in Figure 4) reveals the following. (1) The unbalanced development of e-commerce in each city is quite obvious. Seven out of 11 cities have Gini coefficient of online retail sales greater than 0.4 , which indicates a large e-commerce development gap between districts and county-level cities in the seven cities. Only two cities (Quzhou city and Shaoxing city) have Gini coefficient of online retail sales between 0.2 and 0.3 , which shows an acceptable average level of e-commerce development in the two cities. (2) The imbalance of e-commerce development in cities with high online retail sales is evident. Taking Hangzhou city and Jinhua city as examples, online retail sales in these two cities ranked first and second, respectively, in Zhejiang province nearly every year from 2017 to 2019 (as shown in Figure 2). However, in Hangzhou city, the 3-year Gini coefficients of online retail sales are 0.469, 0.474 , and 0.481 , respectively, during 2017-2019. In Jinhua city, the 3-year Gini coefficients of online retail sales are $0.644,0.633$, and 0.616 , respectively, during the same period. According to the international convention on the Gini coefficient, when the Gini coefficient of online retail sales reaches more than 0.5 , it represents that the level of e-commerce development varies greatly in these cities.

\subsection{Analysis on Spatial Pattern of E-Commerce Development.} Online retail sales data of 89 districts and county-level cities during 2017-2019 in Zhejiang province are imported into ArcGIS Desktop to analyse the spatial aggregation pattern of the e-commerce development level at a more specific spatial scale. The results of 2017, 2018, and 2019 are basically the same, and thus, we only display the result of 2019 in 5-bit colour ramp display mode (as shown in Figure 5).

As we can find from Figure 5, spatial aggregation characteristics of e-commerce development are highly significant. However, high-high clusters indicate that well- 


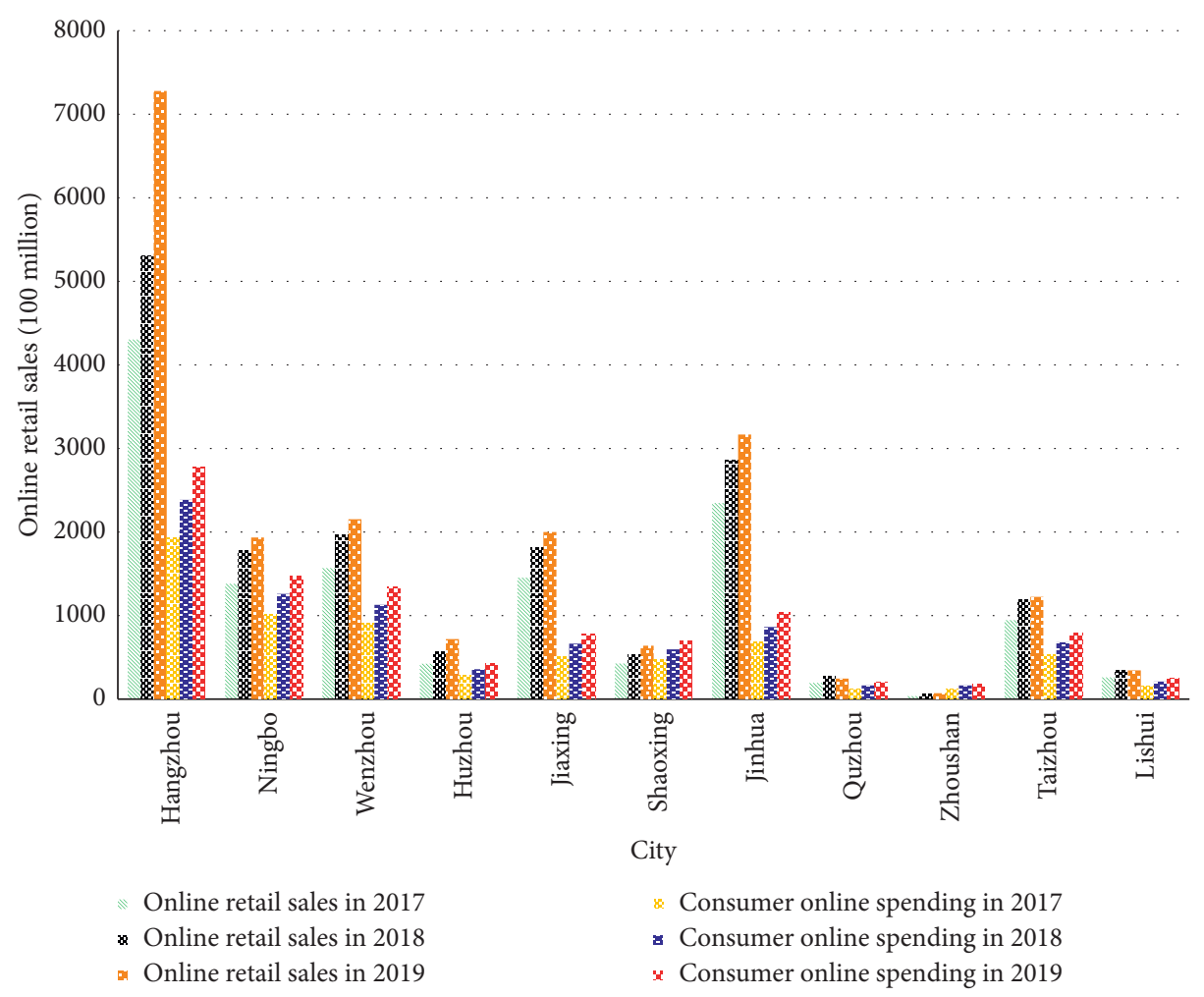

Figure 2: The overall e-commerce trade profile of Zhejiang province.

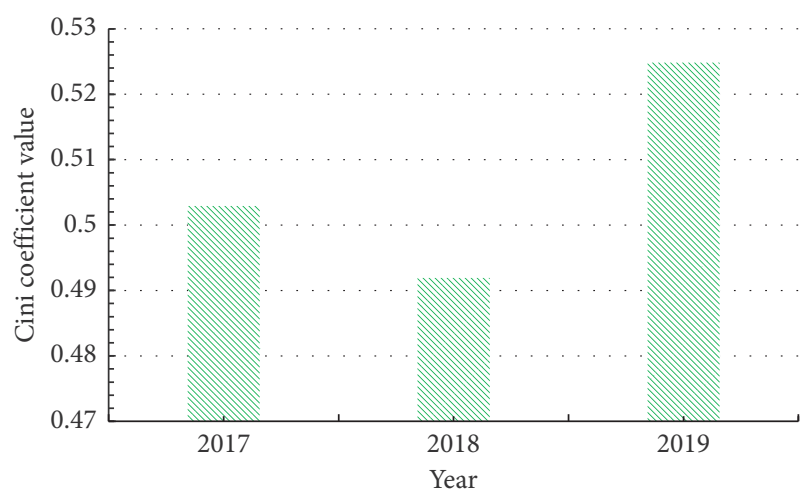

Figure 3: The Gini coefficient of online retail sales in Zhejiang province during 2017-2019.

developed e-commerce districts or county-level cities exist in the middle-north area of Zhejiang province. Meanwhile, there are some low-low clusters which indicate that underdeveloped e-commerce districts or county-level cities exist in the middle-north area of the province. High-high clusters are mainly located in some districts and county-level cities of Hangzhou city, Jinhua city, Huzhou city, and Jiaxing city. Low-low clusters are mainly located in some districts and county-level cities of Quzhou city, Lishui city, and Wenzhou city.

To validate the spatial aggregation of e-commerce development in Zhejiang province quantitatively, we adapt the cluster and outlier analysis (Anselin Local Moran's I) with the help of spatial analyst tools in ArcGIS Desktop. The online retail sales data of 89 districts and county-level cities (with INVERSE_DISTANCE as the conceptualisation and EUCLIDEAN as the distance method) and the spatial autocorrelation analysis report are shown in Figure 6 . According to Anselin Local Moran's I analysis result interpretation specification, the $z$-score of 11.3606 implies less than $1 \%$ likelihood that this clustered pattern could be the result of random chance.

\section{Influence Factors of Spatially Imbalanced E-Commerce Development in Zhejiang Province}

It is generally believed that e-commerce development is influenced to a large extent by many regional economic and social development-related factors. To explore the specific influencing factors and spatial differences of the development of e-commerce in Zhejiang province, we use the GWR and the OLS methods to examine the relationship between the level of economic, social, and technological development and online retail sales at the district or county-level city scale.

6.1. Influence Factors and Model Building. We select online retail sales (OnlineRetailSale) as the dependent variable, and gross domestic product (GDP), per capita gross domestic product (PerGDP), population of permanent residents (Population), administrative area (Area), local financial revenue (LocalRevenue), local transportation expenditure (TransExpenditure), postal revenue (PostalRevenue), 
number of Internet users (InternetUsers), retail sales of consumer goods (RetailSales), urban per capita disposable income (UrbanPerCapitaIncome), rural per capita disposable income (RuralPerCapitaIncome), gross product of transportation, warehousing, and postal services (TransportationWarehousingPostalGross), electricity use of transportation, warehousing, and postal services (TransportationWarehousingPostalElectricity), gross product of wholesale and retail (WholesaleRetail), and gross product of the tertiary industry (TertiaryIndustry) as explanatory variables to build the following GWR model:

$$
\begin{aligned}
y_{i}= & \beta_{0}\left(u_{i}, v_{i}\right)+\sum_{j=1}^{k} \beta_{1}\left(u_{i}, v_{i}\right) x_{i j}(\mathrm{GDP})+\sum_{j=1}^{k} \beta_{2}\left(u_{i}, v_{i}\right) x_{i j}(\text { PerGDP }) \\
& +\sum_{j=1}^{k} \beta_{3}\left(u_{i}, v_{i}\right) x_{i j} \text { (Population) }+\sum_{j=1}^{k} \beta_{4}\left(u_{i}, v_{i}\right) x_{i j} \text { (Area) } \\
& +\sum_{j=1}^{k} \beta_{5}\left(u_{i}, v_{i}\right) x_{i j} \text { (Local Revenue) }+\sum_{j=1}^{k} \beta_{6}\left(u_{i}, v_{i}\right) x_{i j}(\text { TransExpenditure }) \\
& \left.+\sum_{j=1}^{k} \beta_{7}\left(u_{i}, v_{i}\right) x_{i j} \text { (PostalRevenue }\right)+\sum_{j=1}^{k} \beta_{8}\left(u_{i}, v_{i}\right) x_{i j}(\text { InternetUsers }) \\
& +\sum_{j=1}^{k} \beta_{9}\left(u_{i}, v_{i}\right) x_{i j} \text { (RetailSales) }+\sum_{j=1}^{k} \beta_{10}\left(u_{i}, v_{i}\right) x_{i j}(\text { UrbanPerCapitaIncome }) \\
& +\sum_{j=1}^{k} \beta_{11}\left(u_{i}, v_{i}\right) x_{i j}(\text { RuralPerCapitaIncome })+\sum_{j=1}^{k} \beta_{12}\left(u_{i}, v_{i}\right) x_{i j}(\text { TransportationWarehousingPostalGross }) \\
& \left.+\sum_{j=1}^{k} \beta_{13}\left(u_{i}, v_{i}\right) x_{i j} \text { (TransportationWarehousingPostalElectricity }\right)+\sum_{j=1}^{k} \beta_{14}\left(u_{i}, v_{i}\right) x_{i j}(\text { WholesaleRetail }) \\
& +\sum_{j=1}^{k} \beta_{15}\left(u_{i}, v_{i}\right) x_{i j} \text { (TertiaryIndustry) }+\varepsilon_{i}, \quad i=1,2,3, \ldots, n .
\end{aligned}
$$

6.2. Regression Result Analysis. Table 1 reports the results of the GWR analysis in ArcGIS Desktop 10.7. In the table, the adjusted $R^{2}$ value is 0.789332616 , which indicates that the established GWR model can explain about $78.9 \%$ of the spatial distribution of e-commerce development in Zhejiang province. Also, the adjusted $R^{2}$ value indicates a strong spatial autocorrelation of e-commerce development with the selected economic and social development related factors (OnlineRetailSale, GDP, PerGDP, Population, Area, LocalRevenue, TransExpenditure, PostalRevenue, InternetUsers, RetailSales, UrbanPerCapitaIncome, RuralPerCapitaIncome, TransportationWarehousingPostalGross TransportationWarehousing, PostalElectricity, WholesaleRetail, and TertiaryIndustry) at the district or countylevel city scale.

In addition, the OLS model is used for multivariate stepwise regression analysis to explore a strong correlation between some variables and eliminate the influence of multicollinearity. The optimal model is selected according to the fitting effect, and the results are shown in Tables 2 and 3. In the two tables, an asterisk beside a number is used to label a statistically significant $p$ value $(p<0.01)$.

In Table 2, we find that six variables, LocalRevenue, PostalRevenue, InternetUsers, RetailSales,
TransportationWarehousingPostalGross, and TertiaryIndustry, are closely related to the dependent variable. Among these variables, TertiaryIndustry is negatively related to the dependent variable OnlineRetailSale. This may be because TertiaryIndustry (gross product of the tertiary industry) includes the gross product from many industries, such as transportation, warehousing, and postal services, information transmission, computer services and software industry, wholesale and retail trade, accommodation and catering industry, finance, real estate, leasing, and business services, scientific research, technical services and geological survey, water conservancy, environment, and public facilities management, residents' services and other services, education, health, social security and social welfare, culture, sports and entertainment, public administration, and social organisations, international organisations, and other industries.

Internet users, logistics, express delivery, and warehousing are important parts in the development of e-commerce, and therefore, it is consistent with our common sense that postal revenue (PostalRevenue), number of Internet users (InternetUsers), gross product of transportation, warehousing, and postal services 


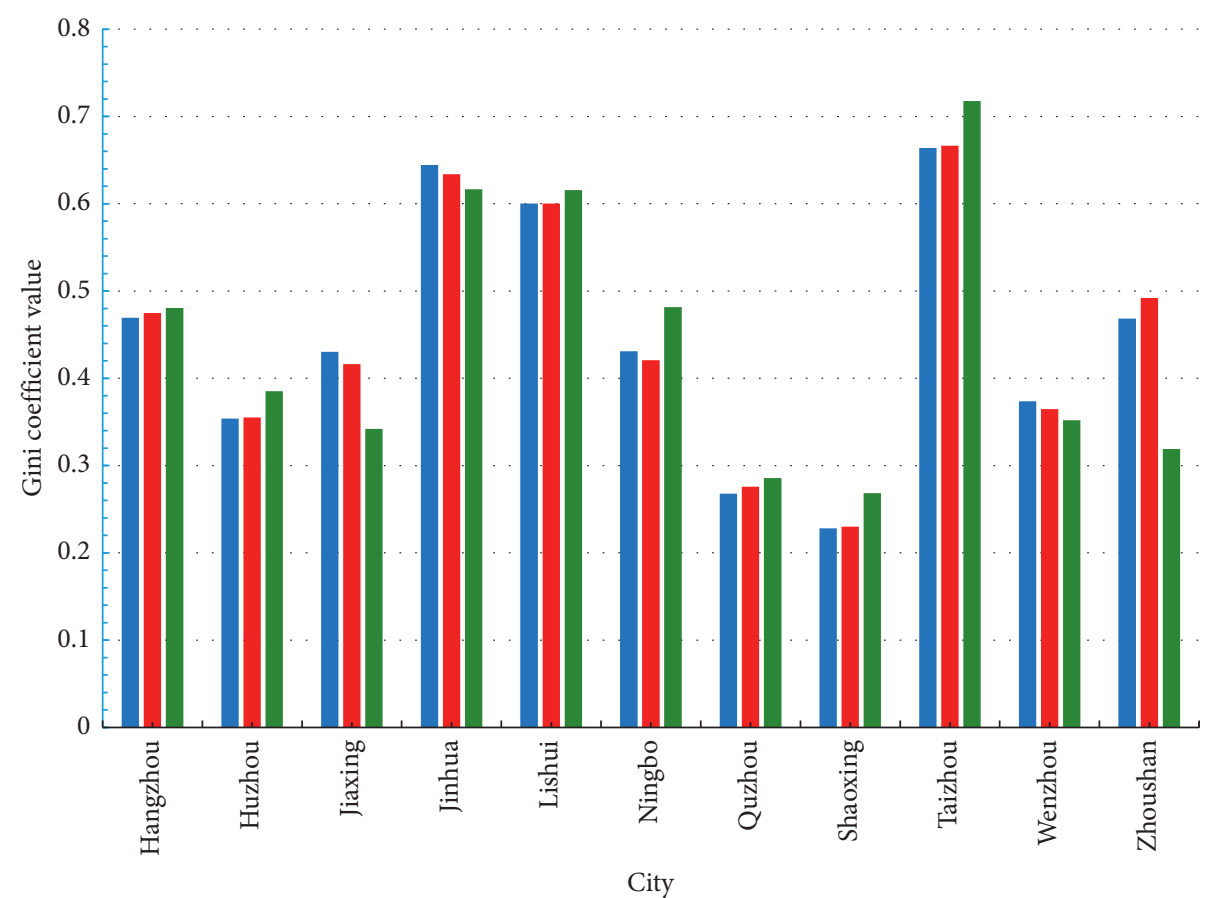

- Gini coefficient in 2017

- Gini coefficient in 2018

- Gini coefficient in 2019

Figure 4: The Gini coefficient of online retail sales in cities of Zhejiang province.

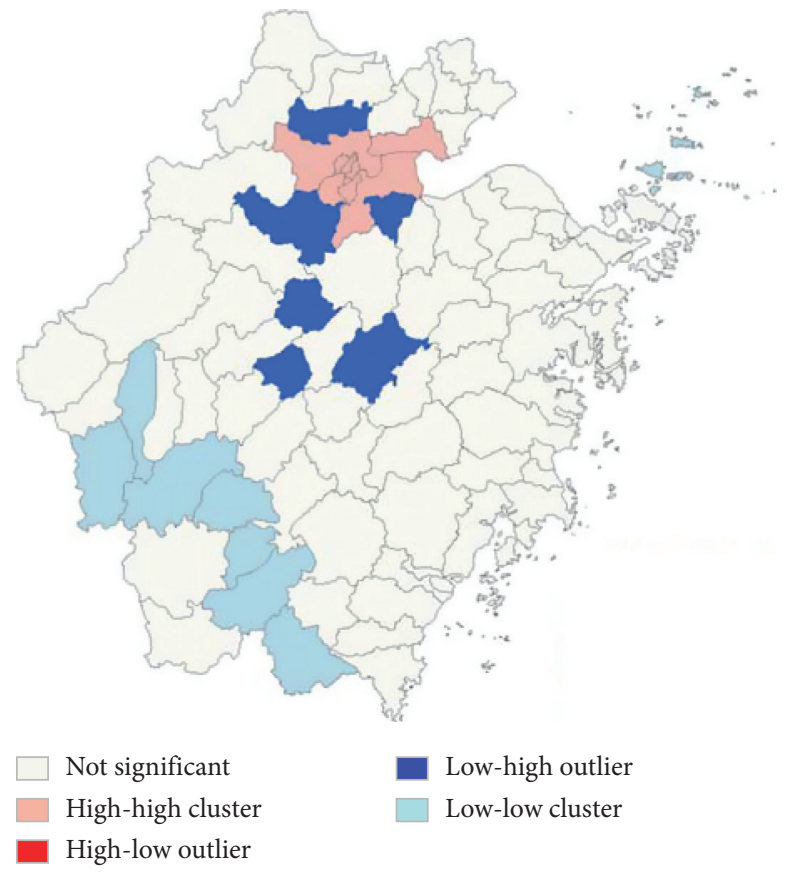

FIgURE 5: Spatial aggregation analysis of online retail sales at the district or county-level city scale.

(TransportationWarehousingPostalGross) are positively related to OnlineRetailSale.

E-commerce-related enterprises account for a large proportion of all enterprises in Zhejiang province, and they pay a large amount of taxes and fees to the government.
This may be the reason why local financial revenue (LocalRevenue) is positively related to OnlineRetailSale. E-commerce in Zhejiang is well developed, and most residents have formed the habit of online shopping which accounts for a large proportion in their daily consumption. 


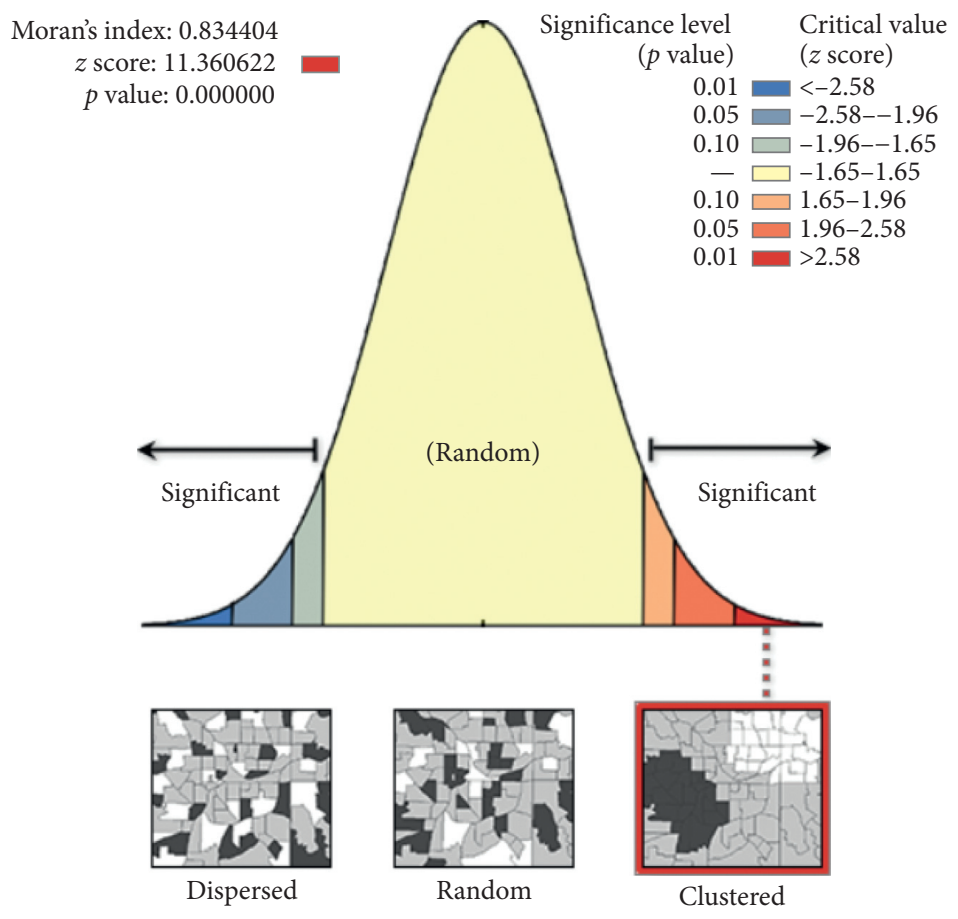

FIGURE 6: Spatial autocorrelation analysis report of online retail sales at the district or county-level city scale.

TABLE 1: GWR analysis result with ArcGIS spatial relationships tool.

\begin{tabular}{lccc}
\hline Object ID & Varname & Variable & Definition \\
\hline 1 & Bandwidth & 1.652645326 & \\
2 & Residual squares & $2.64019 E+14$ & \\
3 & Effective number & 20.43252159 & \\
4 & Sigma & 1962270.415 & OnlineRetailSale \\
5 & AICc & 2851.544042 & GDP \\
6 & $R^{2}$ & 0.789332616 & PerGDP \\
7 & $R^{2}$ adjusted & 0.761287222 & Population \\
8 & Dependent field & 0 & Area \\
9 & Explanatory field & 1 & LocalRevenue \\
10 & Explanatory field & 2 & TransExpenditure \\
11 & Explanatory field & 3 & PostalRevenue \\
12 & Explanatory field & 4 & InternetUsers \\
13 & Explanatory field & 5 & RetailSales \\
14 & Explanatory field & 6 & UrbanPerCapitalIncome \\
15 & Explanatory field & 7 & RuralPerCapitalIncome \\
16 & Explanatory field & 8 & TransportationWarehousingPostalGross \\
17 & Explanatory field & 9 & TransportationWarehousingPostalElectricity \\
18 & Explanatory field & 10 & WholesaleRetail \\
19 & Explanatory field & 11 & TertiaryIndustry \\
20 & Explanatory field & 12 & \\
21 & Explanatory field & 13 & 14 \\
22 & Explanatory field & 15 &
\end{tabular}

This may explain why retail sales of consumer goods (RetailSales) is positively related to OnlineRetailSale.

Table 3 indicates the overall reliability of the OLS analysis result. We do not have multiple models to check the smallest AICc information criterion model. However, the rather high adjusted $R^{2}$ value of 0.7501227 shows a good performance of our GWR model. In addition, the model established in the paper has good fitness according to the evaluation criteria of the joint $F$-statistic, joint Wald statistic, Koenker (BP) statistic, and Jarque-Bera statistic. The residual vs. predicted scatterplot has little structure, and it looks random (as shown in Figure 7). According to the rules for interpretation of OLS analysis results (https://desktop. arcgis.com/zh-cn/arcmap/10.3/tools/spatial-statisticstoolbox/interpreting-ols-results.htm), it indicates a valuable fitness of the proposed e-commerce development spatial 
TABLE 2: Summary of OLS results.

\begin{tabular}{lcccccccc}
\hline Variable & Coefficient & StdError & $\begin{array}{c}\mathrm{t}- \\
\text { statistic }\end{array}$ & Probability & Robust_SE & Robust_t & Robust_Pr & VIF \\
\hline Intercept & 1634599.5 & 2381296 & 0.68643 & 0.494613 & 1764610.88 & 0.92632 & 0.357325 & - \\
GDP & 0.280109 & 0.24274 & 1.15393 & 0.252291 & 0.313456 & 0.89361 & 0.37446 & 23.62808 \\
PerGDP & 3.203353 & 10.797 & 0.29669 & 0.76755 & 5.963631 & 0.53715 & 0.592802 & 6.151398 \\
Population & -760.6725 & 19370 & -0.03927 & 0.968779 & 22906.3123 & -0.03321 & 0.973596 & 9.036138 \\
Area & -652.6249 & 464.224 & -1.40584 & 0.164018 & 512.886693 & -1.27245 & 0.207252 & 2.505199 \\
LocalRevenue & 0.085829 & 0.59704 & 0.14376 & $0.036086^{*}$ & 0.889384 & 0.0965 & $0.023381^{*}$ & 6.103148 \\
TransExpenditure & 7.124505 & 14.3365 & 0.49695 & 0.620723 & 18.430816 & 0.38655 & 0.700216 & 2.497873 \\
PostalRevenue & 6.475981 & 3.27634 & 1.97659 & $0.031866^{*}$ & 5.105642 & 1.2684 & $0.0208688^{*}$ & 2.057148 \\
InternetUsers & 41532.433 & 20297.3 & 2.0462 & $0.044338^{*}$ & 12422.2993 & 3.34338 & $0.001313^{*}$ & 3.072969 \\
RetailSales & 0.559669 & 0.28557 & 1.95987 & $0.02383^{*}$ & 0.259745 & 2.15469 & $0.034483^{*}$ & 6.76502 \\
UrbanPerCapitalIncome & 47.106312 & 70.0908 & 0.67208 & 0.503656 & 54.03746 & 0.87173 & $0.0386206^{*}$ & 7.373611 \\
RuralPerCapitalIncome & -187.5783 & 98.2379 & -1.90943 & 0.070138 & 75.432815 & -2.48669 & $0.015177^{*}$ & 6.453628 \\
TransportationWarehousingPostalGross & 0.30451 & 0.5212 & -0.58424 & $0.016086^{*}$ & 0.2266 & 1.34382 & $0.0183172^{*}$ & 1.127603 \\
TransportationWarehousingPostalElectricity & 21.390363 & 27.1108 & 0.789 & 0.432664 & 31.238967 & 0.68473 & 0.495678 & 1.178223 \\
WholesaleRetail & 0.04045 & 0.21772 & 0.18579 & 0.853121 & 0.243053 & 0.16643 & 0.868281 & 1.460752 \\
TertiaryIndustry & -0.579123 & 0.23344 & -2.48085 & $0.015408^{*}$ & 0.252954 & -2.28944 & $0.024943^{*}$ & 5.212943 \\
\hline
\end{tabular}

TABLE 3: OLS diagnostics report.

\begin{tabular}{lccc}
\hline Input features & & Dependent variable & OnlineRetailSale \\
\hline Number of observations & 89 & Akaike's information criterion (AICc) & 2876.63345 \\
Multiple $R$-squared & 0.586245 & Adjusted $R$-squared & 0.7501227 \\
Joint F-statistic & 6.89554 & Prob $(>F),(15,73)$ degrees of freedom & $0.000000^{*}$ \\
Joint Wald statistic & 207.832259 & Prob (>chi-squared), (15) degrees of freedom & $0.000000^{*}$ \\
Koenker (BP) statistic & 34.123774 & Prob (>chi-squared), (15) degrees of freedom & $0.003272^{*}$ \\
Jarque-Bera statistic & 204.382134 & Prob (>chi-squared), (2) degrees of freedom & $0.000000^{*}$ \\
\hline
\end{tabular}

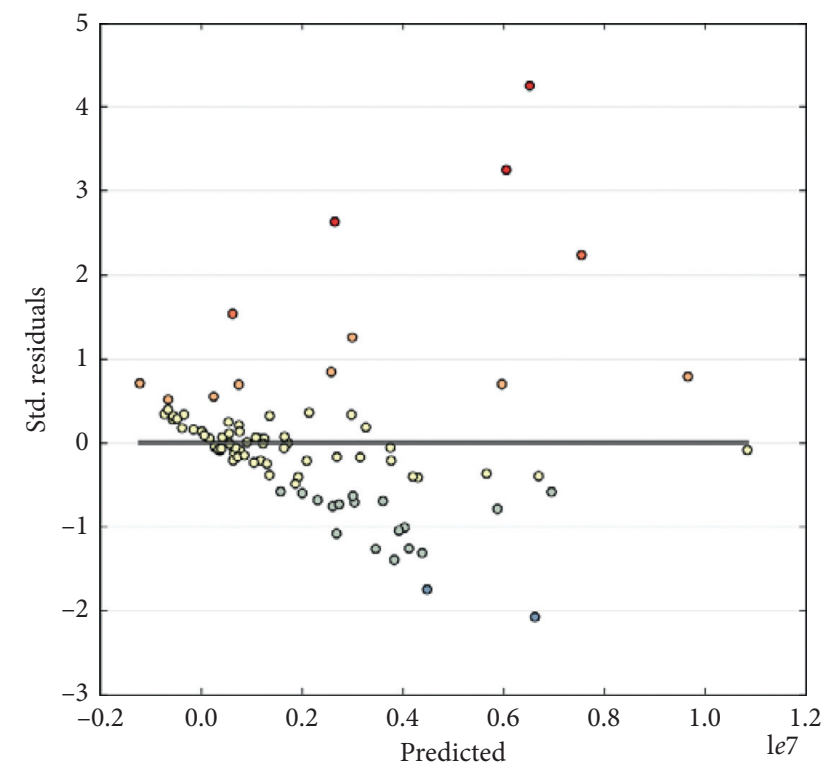

Figure 7: Residual vs. predicted plot.

distribution influencing the GWR model in the previous section.

\section{Conclusions}

A number of studies have shown that the rapid and widespread application of e-commerce is shaping the new business model and order in China, which has a profound influence on the industrial spatial organisation. Also, the unbalanced development of e-commerce in China is very prominent. As one of the earliest and fastest provinces to develop e-commerce in China, Zhejiang has maintained the momentum of rapid growth in recent years. Undoubtedly, the rapid development of e-commerce has promoted the regional economic transformation and development in the province to a large extent. In this paper, we focus on the empirical study of spatial imbalance and the impact factors of regional e-commerce development in Zhejiang, China. Based on the existing theoretical analysis framework, we collect three types of publicly available datasets to analyse quantitatively. The main results coming from our study lie in the following three aspects:

(1) The Gini coefficient based analysis shows that the unbalanced development of e-commerce in Zhejiang province is very serious during 2017-2019. Generally, the lowest Gini coefficient was 0.491 in 2018, and it reached 0.525 in 2019, which indicates a large e-commerce development gap, according to international practice. At the city level, online retail sales of the provincial capital city of Zhejiang province, Hangzhou city, and Jinhua city rank first and second, respectively. The online retail sales of Zhoushan city and Lishui city are relatively low. However, city-level analysis shows that the unbalanced development of e-commerce in cities with large online retail sales is quite serious. Taking Jinhua city as an example, Gini coefficients of online 
retail sales were $0.644,0.633$, and 0.616 , respectively, from 2017 to 2019.

(2) Quantitative analysis shows that the spatial aggregation of e-commerce development is highly significant. With the help of spatial analyst tools in ArcGIS Desktop, the spatial pattern of e-commerce development at the district or county-level city scale is explored. And, we find high-high clusters which indicate that well-developed e-commerce districts or county-level cities exist in the middle-north area of Zhejiang province. Specifically, these clusters are mainly located in some districts and county-level cities of Hangzhou city, Jinhua city, Huzhou city, and Jiaxing city. Meanwhile, low-low clusters indicate that underdeveloped e-commerce districts or county-level cities exist in the middle-north area of the province. These clusters are mainly located in some districts and county-level cities of Quzhou city, Lishui city, and Wenzhou city. The spatial quantitative analysis validated by Anselin Local Moran's I shows more than $99 \%$ likelihood that the clustered pattern of Zhejiang province is dependable.

(3) Geostatistical analysis shows that some economic and social development-related factors can explain the spatial pattern of e-commerce in Zhejiang province. We collect 15 economic and social development indicators of each district or countylevel city as explanatory variables and online retail sales as the dependent variable to establish a GWR model. GWR analysis and OLS analysis indicate that the established model can explain about $78.9 \%$ of the spatial pattern of e-commerce development. We find that local financial revenue, postal revenue, number of Internet users, retail sales of consumer goods, gross product of transportation, warehousing, and postal services, and gross product of the tertiary industry are highly correlated with online retail sales. Specifically, local financial revenue, postal revenue, number of Internet users, retail sales of consumer goods, and gross product of transportation, warehousing, and postal services are highly positively correlated with online retail sales. Gross product of the tertiary industry and online retail sales are highly negatively correlated.

China is the largest e-commerce market in the world and has maintained rapid development in recent years. The development of e-commerce in China has its own special reasons that are closely related to population, geographical environment, traffic conditions, and economic and social development factors. Our findings come from the study of Zhejiang province that give birth to the world's super e-commerce giant Alibaba Group. The statistical index system of regional e-commerce and economic and social development in other countries may vary from China. However, the development of e-commerce is inevitably affected by regional economic development and geographical pattern. Therefore, we believe the findings of the paper can also give a good reference for other countries or regions to improve the development of e-commerce.

Due to data collection and availability reasons, we just collect 15 social and economic related indictors to explore the relationship between them and the spatial aggregation of e-commerce development in Zhejiang province. There may be many other factors that impact the spatial distribution of e-commerce development in the province. This is one of the points that we need to further study in the future. In addition, we also intend to look for data from other countries besides China for comparative study.

\section{Data Availability}

The data used to support the findings of the study are available at http://www.zcom.gov.cn/.

\section{Conflicts of Interest}

The authors declare that they have no conflicts of interest.

\section{Acknowledgments}

The study was partly supported by the Zhejiang Province Philosophy and Social Science Planning "Zhijiang Youth Project" (Grant no. 19ZJQN20YB), Zhijiang Youth Action Project: Study on Mobile E-Commerce Recommendation (Grant no. G306), Ningbo Natural Science Foundation Key Project (Grant no. 2019A610046), Ningbo Philosophy and Social Science Planning Project (project title: the Role and Development Strategy of Cross-border e-commerce in Ningbo's Transition from a Big Foreign Trade City to a Strong Foreign Trade City), Public Technology Research Project of Zhejiang Province (Grant no. LGF20F020004), Humanities and Social Sciences Research Project of the Ministry of Education of China (Grant no. 20YJAZH130), and Achievements of scientific research and innovation team project of Zhejiang Wanli University in 2021.

\section{References}

[1] Mo Fangli and S. Jia, China's E-Commerce Report (2018), Department of E-Commerce and Information Technology, Ministry of Commerce of China, Beijing, China, 2019.

[2] K. M. Nahiduzzaman, A. S. Aldosary, and I. Mohammed, "Framework analysis of E-commerce induced shift in the spatial structure of a city," Journal of Urban Planning and Development, vol. 145, no. 3, Article ID 04019006, 2019.

[3] F. K. Andoh-Baidoo, K.-M. Osei-Bryson, K. AmoakoGyampah, and K. Amoako-Gyampah, "Effects of firm and IT characteristics on the value of e-commerce initiatives: an inductive theoretical framework," Information Systems Frontiers, vol. 14, no. 2, pp. 237-259, 2012.

[4] I. Cárdenas, J. Beckers, and T. Vanelslander, "E-commerce last-mile in Belgium: developing an external cost delivery index," Research in Transportation Business \& Management, vol. 24, pp. 123-129, 2017. 
[5] D. R. Agrawal and D. E. Wildasin, "Sales taxation, spatial agglomeration, and the internet," 2019, https://ssrn.com/ abstract $=3009785$.

[6] I. Novo-Corti and M. Barreiro-Gen, "Public policies based on social networks for the introduction of technology at home: demographic and socioeconomic profiles of households," Computers in Human Behavior, vol. 51, pp. 1216-1228, 2015.

[7] B. R. Schlichter and L. Danylchenko, "Measuring ICT usage quality for information society building," Government Information Quarterly, vol. 31, no. 1, pp. 170-184, 2014.

[8] ITU-International Telecommunication Union, "ICT development index 2017,” 2018, http://www.itu.int/net4/ITU-D/ idi/2017/index.html.

[9] European Commission, "Digital economy and society index," 2017, https://digital-agenda-data.eu/datasets/desi/indicators.

[10] World Economic Forum, "Shaping the future of digital economy and society," 2017, https://www.weforum.org/ communities/the-future-of-the-digital-economy-and-society.

[11] J. Gibbs, K. L. Kraemer, and J. Dedrick, "Environment and policy factors shaping global E-commerce diffusion: a crosscountry comparison," The Information Society, vol. 19, no. 1, pp. 5-18, 2003.

[12] Y. Si, X. Li, Z. Wei, and T. Chen, "Spatial transition and restructuring of Taobao villages in Internet+ era," Planners, vol. 32, no. 5, pp. 117-123, 2016.

[13] Y. Tang, "A spatial difference study on China's E-commerce development level," Economic Geography, vol. 35, no. 5, pp. 9-14, 2015.

[14] Y. D. Wei, J. Lin, and L. Zhang, "E-commerce, Taobao villages and regional development in China," Geographical Review, vol. 110, no. 3, pp. 380-405, 2019.

[15] C. Deng, B. Xie, X. Li, Li Yang, D. Zhu, and F. Zhang, "Evaluation of agricultural land intensive use in hunan based on principal component analysis method," Tropical Geography, vol. 31, no. 1, pp. 65-71, 2011.

[16] H. Feilong, B. Wang, and S. Wang, "Influencing factors and spatial difference of E-commerce development level at county scale in northeast China," Area Research Development, vol. 35, no. 4, pp. 16-31, 2016.

[17] X. Wang, J. Ding, and J. Zhao, “The temporal and spatial differentiation of E-commerce development and its driving effect on economic growth-an empirical analysis based on China's inter-provincial panel data," Jiangsu Agricultural Science, vol. 45, no. 20, pp. 309-314, 2017.

[18] X. Liu, Z. Ding, X. Huang, M. Wang, and F. Wang, "Spatial distribution characteristics and influence factors of E-commerce development level in China: based on EDI of 1915 counties," Economic Geography, vol. 38, no. 11, pp. 11-21, 2018.

[19] J. Yu, L. Wang, and N. Li, "E-shops spatial distribution rule: a case study of Taobao net," Economic Geography, vol. 30, no. 8, pp. 1248-1253, 2010.

[20] C. Zhang, C. Chen, D. Streimikiene, and T. Balezentis, "Intuitionistic fuzzy multimoora approach for multi-criteria assessment of the energy storage technologies," Applied Soft Computing, vol. 79, pp. 410-423, 2019.

[21] H. Zhong, S. Zhang, L. Hua, and Y. Nie, "Spatial pattern of C2C E-commerce online shops in China," Economic Geography, vol. 34, no. 4, pp. 91-96, 2014.

[22] B. Zhu, Y. Song, G. Li, and T. Yu, "Spatial aggregation pattern and influencing factors of Taobao village in China under the C2C E-commerce mode," Economic Geography, vol. 36, no. 6, pp. 92-98, 2016.
[23] P. J. Lambert and J. R. Aronson, "Inequality decomposition analysis and the Gini coefficient revisited," The Economic Journal, vol. 103, no. 420, pp. 1221-1227, 1993.

[24] L. Anselin, "Spatial econometrics: methods and models," Economic Geography, vol. 65, no. 2, pp. 160-162, 1989.

[25] C. Yan-guang, "Reconstructing the mathematical process of spatial autocorrelation based on Moran's statistics," Geographical Research, vol. 28, no. 6, pp. 1449-1463, 2009.

[26] M. Tiefelsdorf, "The saddlepoint approximation of Moran's I's and local Moran's II's reference distributions and their numerical evaluation," Geographical Analysis, vol. 34, no. 3, pp. 187-206, 2002.

[27] Y. Tillé, M. M. Dickson, G. Espa, and D. Giuliani, "Measuring the spatial balance of a sample: a new measure based on Moran's I index," Spatial Statistics, vol. 23, pp. 182-192, 2018.

[28] T. B. Carrijo and A. R. da Silva, "Modified Moran's I for small samples," Geographical Analysis, vol. 49, no. 4, pp. 451-467, 2017.

[29] C.-H. Lin and T.-H. Wen, "Using geographically weighted regression (GWR) to explore spatial varying relationships of immature mosquitoes and human densities with the incidence of dengue," International Journal of Environmental Research and Public Health, vol. 8, no. 7, pp. 2798-2815, 2011.

[30] S. Farber and A. Páez, "A systematic investigation of crossvalidation in GWR model estimation: empirical analysis and Monte Carlo simulations," Journal of Geographical Systems, vol. 9, no. 4, pp. 371-396, 2007.

[31] W. Mijia, "Analysis of endogenous growth factors in China's macro economy: an empirical analysis based on the geographical weighted regression (GWR) model," China Economic Studies, vol. 3, pp. 24-30, 2009. 